\title{
DISTRIBUIÇÃO DE PALHA POR COLHEDORAS AUTOPROPELIDAS NA COLHEITA DA SOJA ${ }^{1}$
}

\section{VILSON L. KUNZ², ANTONIO GABRIEL FILHO ${ }^{3}$, MARCELO A. PRIMO ${ }^{4}$, FLAVIO GURGACZ ${ }^{4}$, EMERSON FEY ${ }^{5}$}

\begin{abstract}
RESUMO: A dificuldade de obter distribuição uniforme dos resíduos, na largura de corte da plataforma da colhedora, tem sido constatada visualmente em culturas comerciais. Assim, o objetivo deste trabalho foi avaliar a uniformidade de distribuição transversal de palha por colhedoras autopropelidas na colheita da soja. Foram avaliadas nove colhedoras nas condições de operação e regulagem que estavam sendo usadas pelo operador. Foi utilizado o coeficiente de variação para a comparação das máquinas e a avaliação da uniformidade de distribuição, e realizada análise multivariada para avaliar a similaridade entre as colhedoras em função do coeficiente de variação, umidade da palha e largura da plataforma de corte. Todas as colhedoras apresentaram distribuição desuniforme de palha, resultando em faixas com elevada concentração da mesma na parte central da linha de deslocamento da colhedora e pouca nas extremidades, independentemente da largura da plataforma de corte. Apenas uma colhedora apresentou distribuição próxima da ideal, por possuir também um sistema distribuidor para a palha proveniente das peneiras. Constatou-se que a palha oriunda das peneiras da colhedora pode ser a responsável pela formação das faixas com elevadas quantidades de palha na linha central, independentemente do tamanho da máquina.
\end{abstract}

PALAVRAS-CHAVE: máquinas agrícolas, plantio direto, resíduo vegetal.

\section{STRAW DISTRIBUTION FOR COMBINES IN THE HARVEST OF SOYBEAN}

\begin{abstract}
The difficulty of getting a uniform residues distribution, in the width of the combine cutting ban, have been observed in crop fields. The objective of this work was to evaluate the uniformity of straw distribution for combines harvesting soybean. It was appraised nine combines in the operation conditions and adjustment that they were being used by the operator. The Coefficient of Variation (CV) was used for comparison of the machines and the evaluation of the distribution uniformity, and had accomplished a multivariate analysis to evaluate the similarity among the combines in function of the coefficient of variation, humidity of the straw and width of the cut platform. All the combines had presented a disuniform straw distribution, resulting in bands, with raised straw concentration in the combine central part and little in the extremities, independently of the width of the cut platform. But a combine presented distribution next to the ideal, for also possessing a delivering system for the straw proceeding from the bolters. One evidenced that the deriving straw of the combine bolters can be the responsible for the formation of bands with raised amounts of straw in the combine center, independently of the machine size.
\end{abstract}

KEYWORDS: agricultural machines, no tillage, plants residue.

\footnotetext{
${ }^{1}$ Extraído da dissertação de mestrado do primeiro autor.

${ }^{2}$ Eng $^{\mathrm{o}}$ Agrônomo, M.Sc. em Engenharia Agrícola, UNIOESTE, Cascavel - PR, Fone: (0XX45) 3220-3199, vilsonkunz@yahoo.com.br

${ }^{3}$ Prof. Dr., Centro Ciências Exatas e Tecnológicas, UNIOESTE, Cascavel - PR.

${ }^{4}$ Eng $^{\mathrm{o}}$ Agrônomo, Mestrando em Engenharia Agrícola, UNIOESTE, Cascavel - PR.

${ }^{5}$ Professor, M.Sc., Centro de Ciências Agrárias, UNIOESTE, Marechal Cândido Rondon - PR.

Recebido pelo Conselho Editorial em: 23-2-2007
}

Aprovado pelo Conselho Editorial em: 7-11-2007 


\section{INTRODUÇÃO}

Em áreas que utilizam o sistema plantio direto, é necessário manejo adequado dos restos culturais ou da cultura implantada para servir de cobertura morta. No caso de restos culturais, o manejo mecânico da palhada começa na operação de colheita, visto que o fracionamento e a distribuição da palha que passa no interior da colhedora, são de fundamental importância para o adequado funcionamento da semeadora. Mas, a presença de palha em si não é garantia de sucesso. Segundo LEVIEN et al. (2004), é importante que essa palha esteja bem distribuída sobre o solo para evitar a ocorrência de locais com acúmulo, causando problemas de embuchamento de semeadoras, emergência irregular de plântulas e, por outro lado, provocar o aparecimento de faixas de fertilidade diferente, ou áreas mais suscetíveis à erosão e maior emergência de plantas daninhas.

Apesar de existirem várias formas e máquinas para o manejo dos resíduos, a colhedora tem importância fundamental, pois, segundo ALBERTA (1999) e AGRICULTURE, FOOD AND RURAL DEVELOPMENT (2005), é a maneira mais prática de manejar o resíduo da colheita, uma vez que, por meio dela, pode-se determinar a altura de corte, cortar e espalhar a palha e o palhiço uniformemente na lavoura.

Atualmente, a maioria das máquinas disponíveis no mercado possui somente o picador com aletas difusoras para distribuir a palha, sem a presença de mecanismo distribuidor de palha proveniente das peneiras. Para AGRICULTURE, FOOD AND RURAL DEVELOPMENT (2005), dois tipos de mecanismos espalhadores de resíduo podem estar disponíveis nas colhedoras. Um deles usa o picador para a palha do saca-palha e um distribuidor de palhiço separado, na saída das peneiras da colhedora. O outro tipo mistura o palhiço com a palha do saca-palha e promove a distribuição dos dois, simultaneamente.

Colhedoras com plataformas de 9,14 m ou mais já estão disponíveis no mercado, porém a maioria delas não está equipada para espalhar, de maneira uniforme, esses maiores volumes de fitomassa (VESETH et al., 1997). Segundo esses autores, em trigo, o problema de distribuição de resíduo tem crescido muito nas últimas duas décadas, devido, principalmente, ao aumento da largura de corte das colhedoras e ao uso de variedades mais altas.

Na cultura da soja, a situação não é diferente. ORLANDO et al. (2005b), em estudo avaliando diversas colhedoras na colheita da soja, verificaram que houve irregularidade na distribuição da palha pelas colhedoras, independentemente da largura de corte. Citam, ainda, que essa irregularidade na distribuição ocasiona disponibilidade desuniforme de nutrientes, com maiores teores nas faixas onde ocorre a deposição da palha proveniente das peneiras da colhedora. Os autores destacam a importância de um sistema de distribuição de palhiço (material proveniente das peneiras) para conseguir distribuição de palha mais próxima do ideal.

Em face desses problemas, o presente trabalho teve por objetivo avaliar a distribuição transversal de palha por colhedoras autopropelidas na colheita da soja.

\section{MATERIAL E MÉTODOS}

O trabalho foi realizado no Laboratório de Mecanização Agrícola, da Universidade Estadual do Oeste do Paraná, Câmpus de Cascavel - PR. Para caracterizar a distribuição transversal de palha, foram avaliadas a campo nove colhedoras, por ocasião da colheita da soja, em condições normais de operação, em propriedades na região oeste do Paraná. Para a coleta da palha, confeccionou-se um coletor com $10 \mathrm{~m}$ de comprimento por $1 \mathrm{~m}$ de largura, subdividido em seções de $0,5 \mathrm{~m}^{2}$, de acordo com a S396. 2 (ASAE, 1998).

Com a colhedora parada, o coletor era colocado entre os eixos dianteiro e traseiro da máquina. Duas pessoas, uma em cada lado da colhedora, seguravam as extremidades da armação e acompanhavam o deslocamento da máquina até a normalização do fluxo de palha, momento em que o coletor era disposto sobre o chão, coletando-se, dessa forma, a palha proveniente das peneiras e do picador da colhedora, conforme pode ser observado na Figura 1. A palha presente em cada 
subdivisão foi coletada individualmente e acondicionada em sacolas para posterior secagem e pesagem em laboratório.

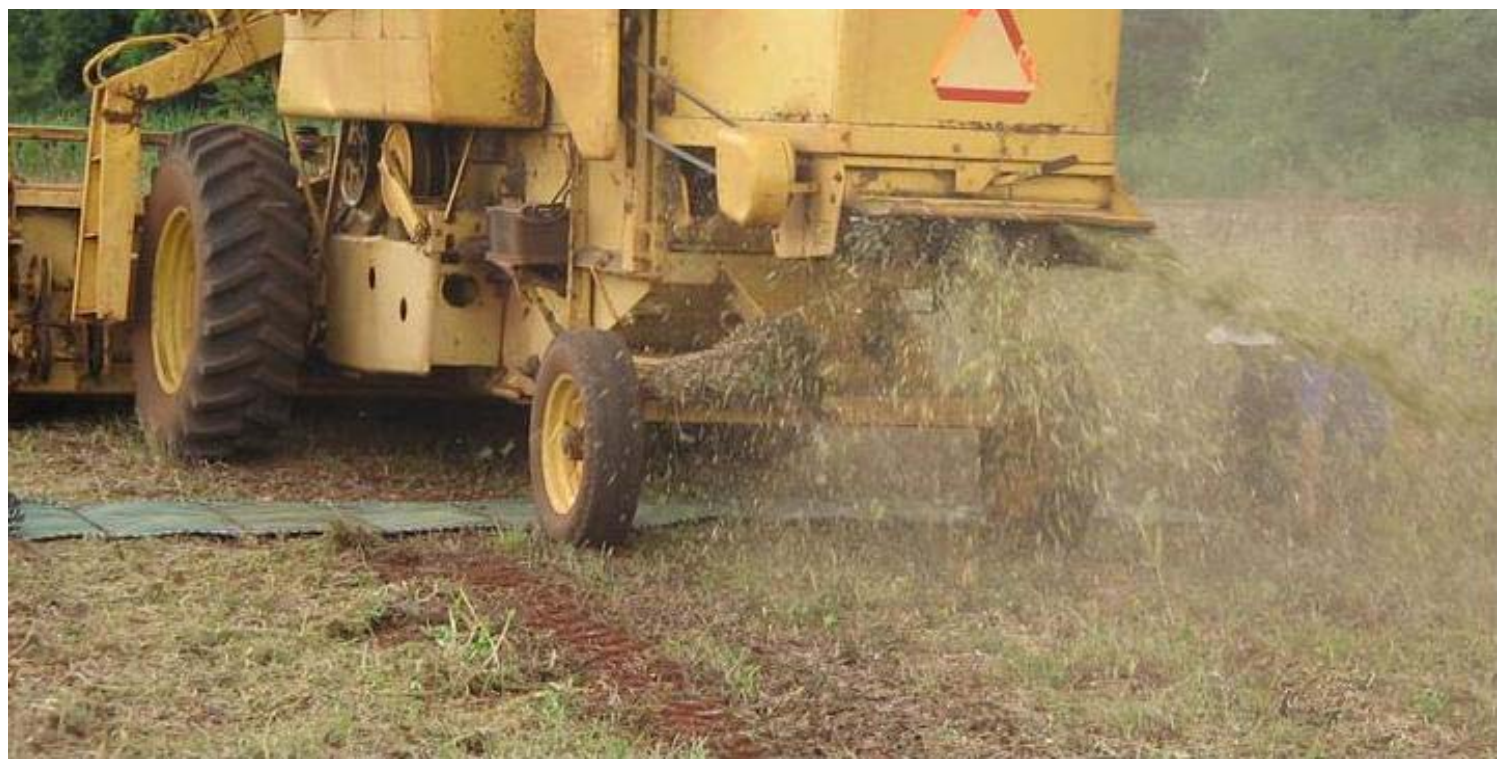

FIGURA 1. Detalhe da coleta de palha da colhedora. Detail of the combine straw collection.

Para cada colhedora, foram realizadas quatro repetições de coleta de palha, nas regulagens que estavam sendo utilizadas pelo operador, e anotadas as características da máquina, que podem ser observadas na Tabela 1.

TABELA 1. Características das colhedoras avaliadas. Characteristics of the evaluated combines.

\begin{tabular}{cccccccc}
\hline Colhedora & $\begin{array}{c}\text { Ano de } \\
\text { fabricação }\end{array}$ & $\begin{array}{c}\text { Sistema } \\
\text { de trilha }\end{array}$ & $\begin{array}{c}\text { Distribuidor } \\
\text { de palhiço }\end{array}$ & $\begin{array}{c}\text { Largura da } \\
\text { Plataforma (m) }\end{array}$ & $\begin{array}{c}\text { Largura das } \\
\text { Peneiras (m) }\end{array}$ & $\begin{array}{c}\mathrm{N}^{\mathrm{o}} \text { de } \\
\text { saca- } \\
\text { palhas }\end{array}$ & $\begin{array}{c}\mathrm{N}^{\mathrm{o}} \text { de } \\
\text { defletores }\end{array}$ \\
\hline A & 1984 & Radial & Não & 3,96 & 1,02 & 4 & 4 \\
B & 1986 & Radial & Não & 3,96 & 1,02 & 4 & 4 \\
C & 1982 & Radial & Não & 3,96 & 0,96 & 4 & 4 \\
D & 1984 & Radial & Não & 3,96 & 0,96 & 4 & 8 \\
E & 1993 & Radial & Não & 4,2 & 1,1 & 4 & 8 \\
F & 2004 & Radial & Sim & 5,76 & 1,5 & 6 & 10 \\
G & 2002 & Radial & Não & 4,86 & 1,24 & 5 & 8 \\
H & 2004 & Radial & Não & 5,76 & 1,52 & 6 & 10 \\
I & 2006 & Axial & Sim & 9,12 & - & - & - \\
\hline
\end{tabular}

O perfil da distribuição transversal das colhedoras apresentado nas Figuras 4 a 12 foi determinado a partir dos valores de massa de palha coletados em cada subdivisão do coletor. Para avaliar a uniformidade de distribuição da palha pelas colhedoras, foi utilizado o coeficiente de variação (C.V.\%) e considerados aceitáveis valores de coeficiente de variação abaixo de $20 \%$, de acordo com as recomendações de GOMES (1982).

A sobreposição da palha nas passadas adjacentes não foi considerada, pois a quantidade de palha que é jogada além da largura de corte da colhedora é pequena, e, em algumas colhedoras, a determinação da distribuição de palha ultrapassou a largura de corte da colhedora pelas características da armação utilizada (subdivisões de $0,5 \mathrm{~m}$ ), o que não permitiu a avaliação na exata largura da plataforma de corte. 
Além disso, a largura de corte da colhedora permanece constante e, dessa forma, a quantidade de palha sobreposta nas passadas adjacentes da colhedora, e embora pudesse mudar o perfil de distribuição da mesma, dificilmente seria considerada pelo operador, em detrimento do rendimento operacional da colheita, ou seja, colher com toda a extensão da plataforma de corte. Assim, a sobreposição da palha foi desconsiderada para efeitos de cálculo neste trabalho.

Também foi realizada análise multivariada dos dados, avaliando a similaridade entre as colhedoras em função do C.V. da distribuição de palha, largura da plataforma de corte e umidade da palha. Para melhor visualização do comportamento da distribuição da palha pelas colhedoras, realizou-se análise estatística descritiva da distribuição transversal para todas as colhedoras.

\section{RESULTADOS E DISCUSSÃO}

As características da colhedora no momento da avaliação e do local, bem como a caracterização da cultura podem ser observadas na Tabela 2.

TABELA 2. Caracterização das condições das avaliações e da cultura para cada colhedora. Characterization of the evaluations and culture conditions for each combine.

\begin{tabular}{ccccccccc}
\hline $\begin{array}{c}\text { Colhe- Velocidade } \\
\text { dora }\end{array}$ & $\begin{array}{c}\text { Umidade } \\
\text { da palha } \\
\left(\mathrm{km} \mathrm{h}^{-1}\right)\end{array}$ & $\begin{array}{c}\text { Declivi- } \\
\text { dade }^{1} \\
(\%)\end{array}$ & $\begin{array}{c}\text { Rotação do } \\
\text { cilindro } \\
(\mathrm{rpm})\end{array}$ & $\begin{array}{c}\text { Abertura do } \\
\text { côncavo } \\
(\mathrm{mm})^{2}\end{array}$ & $\begin{array}{c}\text { Massa } \\
\text { cultura } \\
\left(\mathrm{kg} \mathrm{ha}^{-1}\right)\end{array}$ & $\begin{array}{c}\text { Produti- } \\
\text { vidade }(\mathrm{kg} \\
\left.\text { ha }^{-1}\right)\end{array}$ & $\begin{array}{c}\text { Relação } \\
\text { palha/grão }\end{array}$ \\
\hline $\mathrm{A}$ & 3,5 & 33 & $4 \mathrm{~d}$ & 600 & $25-20$ & 1.300 & 2.950 & 0,44 \\
$\mathrm{~B}$ & 3,2 & 45 & $1 \mathrm{~d}$ & 700 & $20-15$ & 1.740 & 2.300 & 0,76 \\
$\mathrm{C}$ & 4,5 & 15 & 0 & 1.000 & $20-10$ & 2.460 & 3.300 & 0,75 \\
$\mathrm{D}$ & 3,5 & 26 & $2 \mathrm{e}$ & 567 & $25-15$ & 2.170 & 3.660 & 0,59 \\
$\mathrm{E}$ & 4,5 & 35 & $1 \mathrm{e}$ & 700 & $20-10$ & 2.420 & 3.120 & 0,78 \\
$\mathrm{~F}$ & 5 & 10 & $2 \mathrm{e}$ & 800 & $25-15$ & 2.330 & 3.540 & 0,66 \\
$\mathrm{G}$ & 4 & 6 & 0 & 600 & $25-15$ & 2.310 & 3.450 & 0,67 \\
$\mathrm{H}$ & 6,5 & 7 & 0 & 900 & $30-25$ & 2.480 & 3.500 & 0,71 \\
$\mathrm{I}$ & 6 & 30 & $1 \mathrm{~d}$ & - & - & 2.290 & 3.450 & 0,66 \\
\hline
\end{tabular}

${ }^{1}$ Percentagem e sentido da declividade no local de avaliação ( $\mathrm{d}=$ direita; $\mathrm{e}=$ esquerda).

${ }^{2}$ Abertura em relação ao cilindro de trilha, no início e no fim da extensão do côncavo.

As quantidades de palha, bem como a relação palha/grão nas áreas avaliadas foram bastante diferentes, mas não influenciaram na distribuição de palha, pois as colhedoras A e E, por exemplo, embora avaliadas em condições bem diferentes, apresentaram comportamento semelhante em relação à distribuição de palha. O comportamento da distribuição de palha pelas colhedoras é apresentado na Tabela 3.

TABELA 3. Análise descritiva da distribuição transversal de palha das colhedoras. Descriptive analysis of the transversal straw distribution of the combines.

\begin{tabular}{lccccccccc}
\hline Colhedora & $\mathrm{A}$ & $\mathrm{B}$ & $\mathrm{C}$ & $\mathrm{D}$ & $\mathrm{E}$ & $\mathrm{F}$ & $\mathrm{G}$ & $\mathrm{H}$ & $\mathrm{I}$ \\
\hline Média* & 1,30 & 1,74 & 2,46 & 2,17 & 2,42 & 2,33 & 2,31 & 2,48 & 2,29 \\
Mediana* & 1,56 & 1,69 & 2,13 & 1,77 & 2,17 & 2,44 & 1,78 & 1,73 & 2,10 \\
Desvio-Padrão & 0,69 & 0,55 & 1,63 & 1,45 & 1,53 & 0,31 & 1,22 & 1,69 & 1,26 \\
Variância & 0,47 & 0,30 & 2,67 & 2,11 & 2,34 & 0,09 & 1,50 & 2,86 & 1,59 \\
Mínimo* & 0,32 & 0,95 & 0,68 & 0,52 & 0,32 & 1,70 & 1,34 & 0,66 & 0,55 \\
Máximo* & 2,27 & 2,57 & 5,35 & 5,15 & 4,77 & 2,72 & 5,05 & 5,22 & 5,22 \\
Intervalo* & 1,96 & 1,62 & 4,67 & 4,64 & 4,45 & 1,03 & 3,71 & 4,56 & 4,67 \\
C.V. (\%) & 64 & 41 & 74 & 70 & 68 & 28 & 57 & 72 & 61 \\
\hline
\end{tabular}

*valores em $\mathrm{Mg} \mathrm{ha}^{-1}$ 
As colhedoras apresentaram desuniformidade na distribuição da palha dentro da largura da plataforma de corte. A colhedora $\mathrm{F}$ apresentou a distribuição mais uniforme, com menor diferença entre as quantidades de palha coletadas no centro da linha de deslocamento e na extremidade. $\mathrm{Na}$ colhedora $\mathrm{C}$, a diferença entre as quantidades de palha coletada nas subdivisões do coletor chegou a 4,67 $\mathrm{Mg} \mathrm{ha}^{-1}$. Na colhedora $\mathrm{D}$, a quantidade máxima coletada na linha central do deslocamento da colhedora foi aproximadamente dez vezes maior que a quantidade mínima na extremidade, devido, possivelmente, ao acúmulo da palha proveniente das peneiras. Nas colhedoras A e B, a massa de palha da cultura foi menor do que nas demais colhedoras, o que pode ter influenciado na distribuição da mesma. As colhedoras E, G, H e I também apresentaram grande diferença entre a quantidade de palha na extremidade e no centro da linha de deslocamento da colhedora. Essa desuniformidade na distribuição pode ser observada pelos valores do C.V.\%, elevados em todas as colhedoras. De acordo com GOMES (1982), coeficientes de variação acima de $20 \%$ são considerados altos para ensaios agrícolas.

Conforme pode ser observado na Figura 2, todas as colhedoras apresentaram elevado C.V., e a colhedora $\mathrm{F}$ apresentou o menor valor, diferindo das demais colhedoras. Já as colhedoras C, D, E e $\mathrm{H}$ apresentaram os maiores valores.

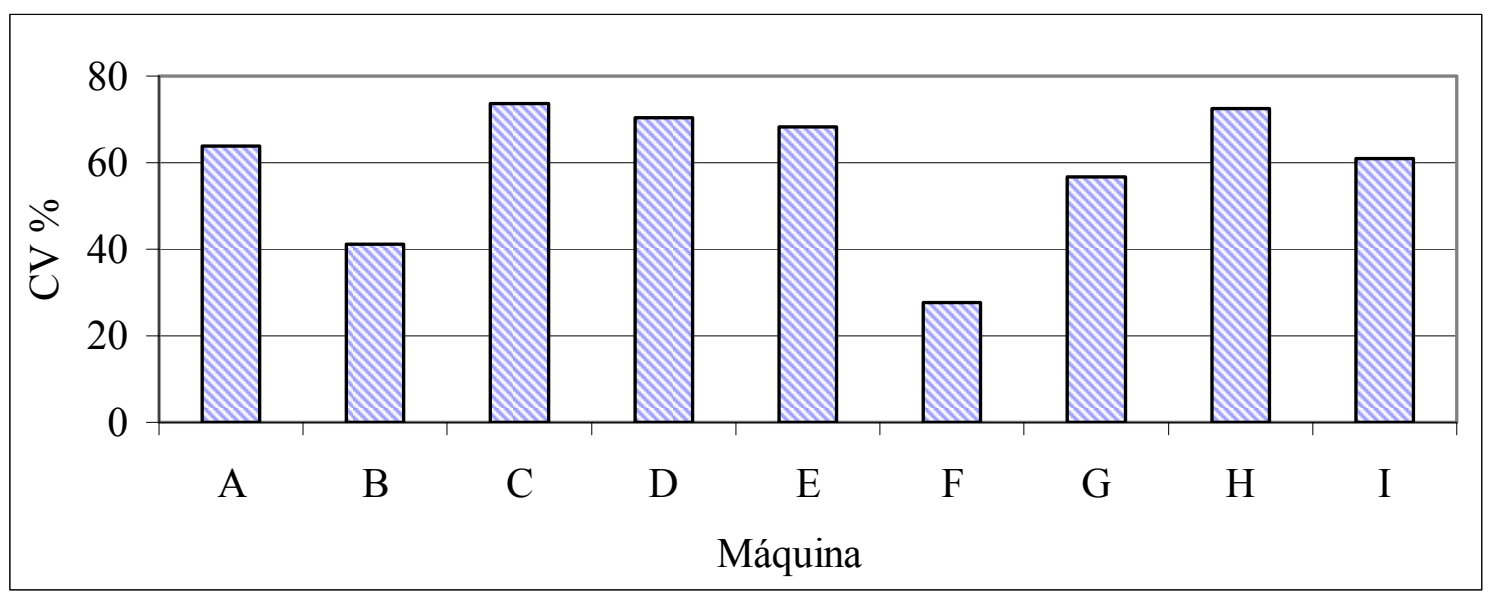

FIGURA 2. Coeficiente de variação (C.V.\%) da distribuição transversal de palha. Coefficient of variation (CV\%) of the transversal straw distribution.

Das máquinas avaliadas, a colhedora $\mathrm{F}$ apresentou a distribuição transversal mais próxima dos índices aceitáveis $(\mathrm{C} . \mathrm{V} .=28 \%)$. Essa colhedora estava equipada com mecanismo para distribuir também a palha proveniente das peneiras. Com esse mecanismo, o material das peneiras é arremessado sobre o distribuidor que lança a palha para os lados, evitando que ela caia diretamente sobre o solo. Dessa forma, a palha não fica acumulada no centro, como ocorre na ausência do equipamento. As colhedoras sem distribuidor para o material proveniente das peneiras apresentaram distribuição menos uniforme, com acúmulo de palha no centro da colhedora, mais especificamente na largura compreendida pelas peneiras da máquina, evidenciando o relato feito por SMITH (1986) sobre a importância da distribuição dos resíduos dessa seção.

A análise multivariada dos dados foi realizada para verificar a similaridade entre as colhedoras, levando em consideração o coeficiente de variação da distribuição da palha (C.V.\%), a largura da plataforma de corte da colhedora (LP, m) e a umidade da palha (Um, \%). O resultado da análise foi o agrupamento das colhedoras em quatro grupos que podem ser visualizados na Figura 3.

Conforme pode ser observado na Figura 3, as colhedoras A, D, E e I constituem o conjunto com maior similaridade, em torno de $95 \%$. As colhedoras $\mathrm{C}, \mathrm{G}$ e $\mathrm{H}$ constituem o segundo conjunto, com similaridade acima de $80 \%$, enquanto as colhedoras B e F aparecem constituindo o terceiro e quarto conjuntos, respectivamente. 
As colhedoras $\mathrm{F}$ e $\mathrm{B}$ constituem conjuntos diferentes e individuais, devido, possivelmente, à influência do C.V.\% dessas colhedoras, que foi de $28 \%$ e $41 \%$, respectivamente, sendo esses valores bem inferiores e diferentes entre si, e em relação às demais colhedoras.

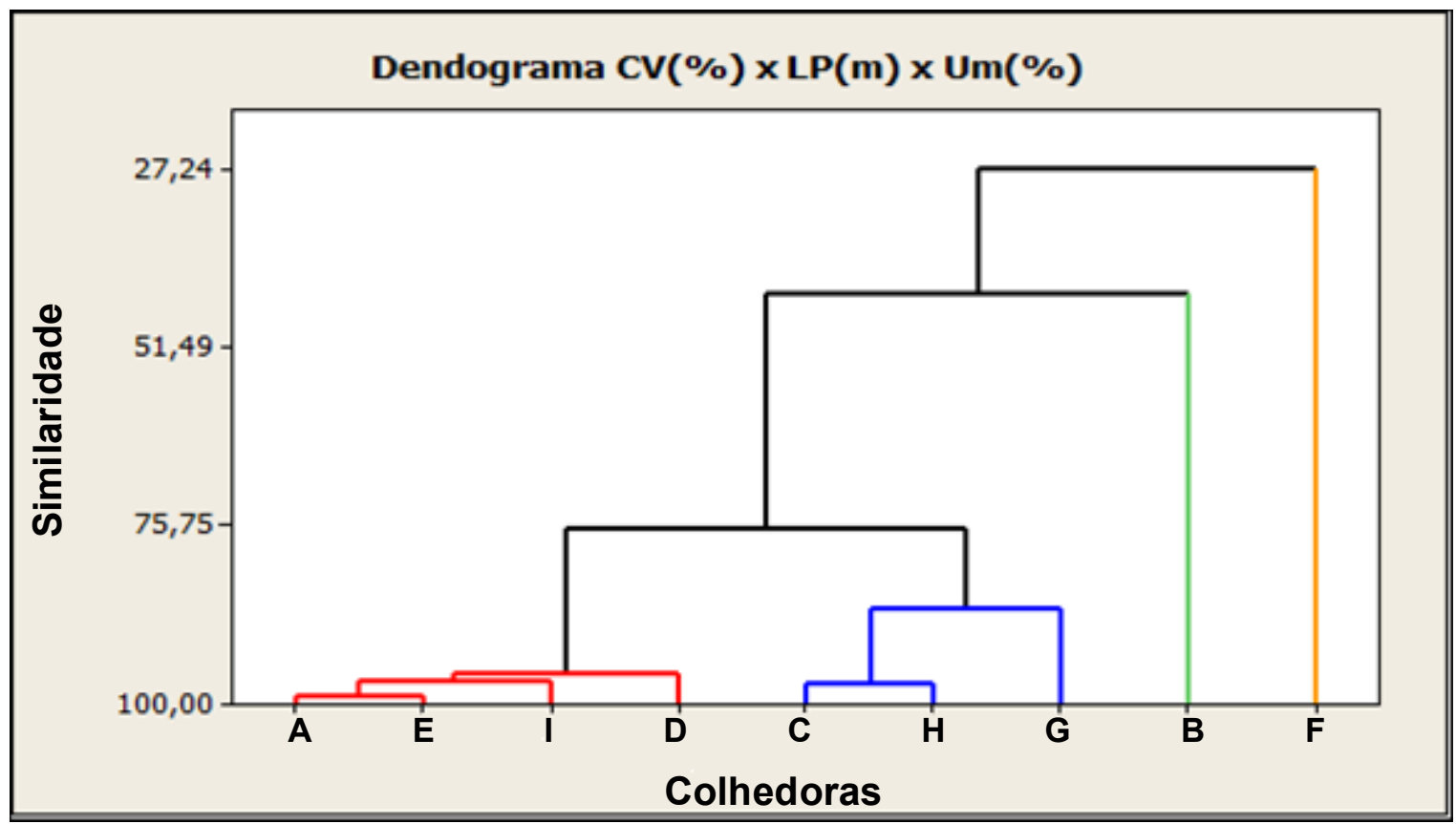

FIGURA 3. Dendograma da análise multivariada das colhedoras. Organization chart of the combine multivariate analysis.

O perfil da distribuição transversal de palha das colhedoras pode ser observado nas Figuras 4 a 12. Nessas Figuras, apresentam-se a distribuição da palha pela colhedora, bem como a largura da plataforma de corte, largura das peneiras e a quantidade média (distribuição ideal) de palha para cada máquina. A quantidade média de palha foi obtida pela relação entre a quantidade de palha coletada e a largura da plataforma de corte da colhedora.

A colhedora A (Figura 4) foi avaliada em área com declividade de $4 \%$ e apresentou distribuição de palha com acúmulo no centro e para a direita da colhedora (lado para o qual a máquina estava inclinada). Quando a colhedora trabalha inclinada, a palha que é recolhida pela plataforma de corte começa a acumular em um lado da colhedora, tanto nas peneiras, como no sacapalha da máquina. Assim, a palha chega ao picador da colhedora concentrada no lado mais baixo (sentido da declividade), resultando em distribuição irregular, com quantidades maiores desse lado.

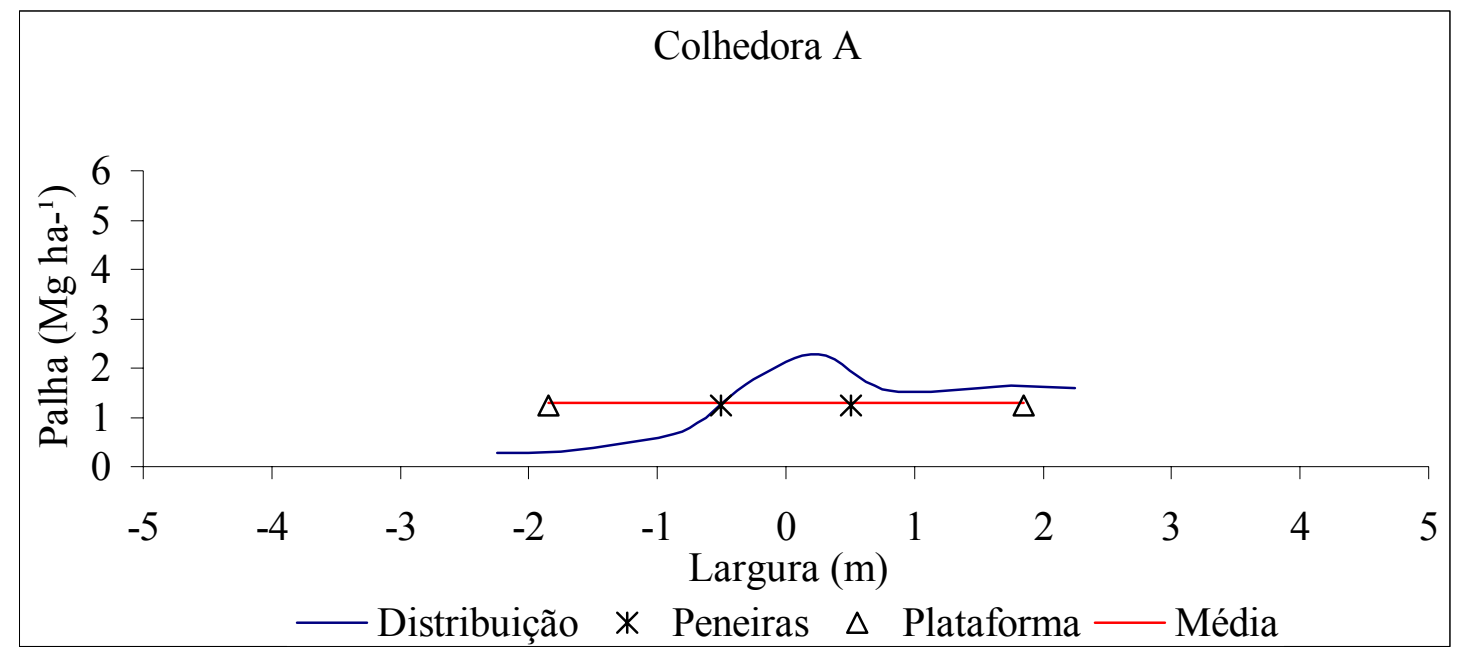

FIGURA 4. Distribuição de palha da colhedora A. Straw distribution of the combine A. 
As colhedoras D (Figura 7) e F (Figura 9), avaliadas em área com 2\% de declividade, e as colhedoras B, E e I (Figuras 5; 8 e 12, respectivamente), avaliadas em áreas com 1\% de declividade, também tiveram distribuição com tendência de acúmulo da palha na direção da inclinação do terreno, embora não de forma tão acentuada quanto na colhedora $\mathrm{A}$, devido à menor declividade da área.

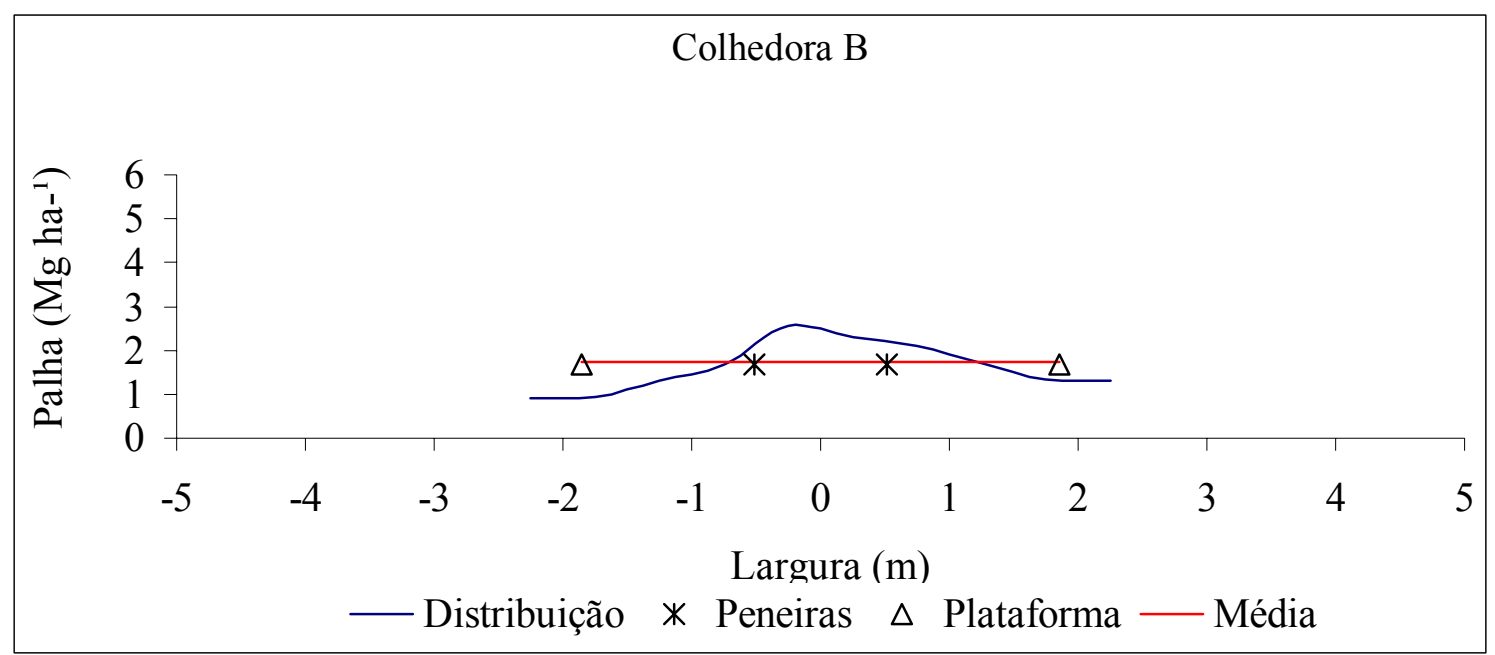

FIGURA 5. Distribuição de palha da colhedora B. Straw distribution of the combine B.

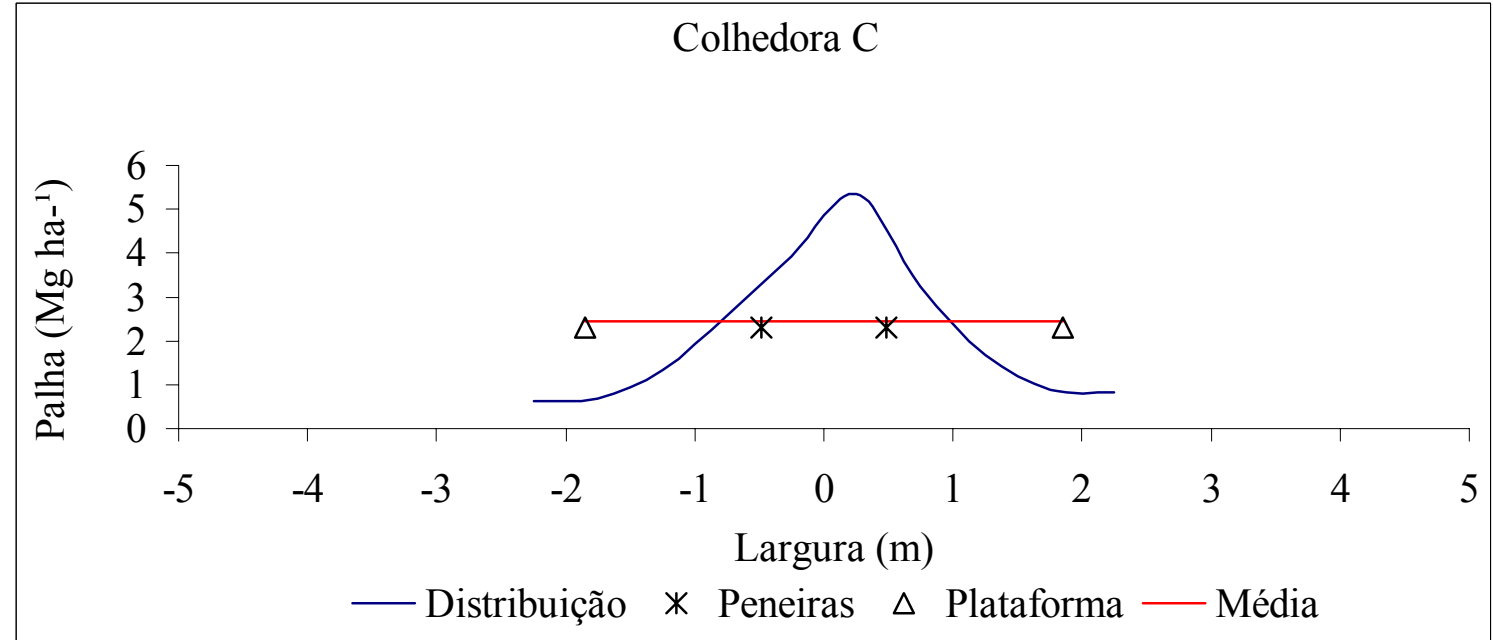

FIGURA 6. Distribuição de palha da colhedora C. Straw distribution of the combine C.

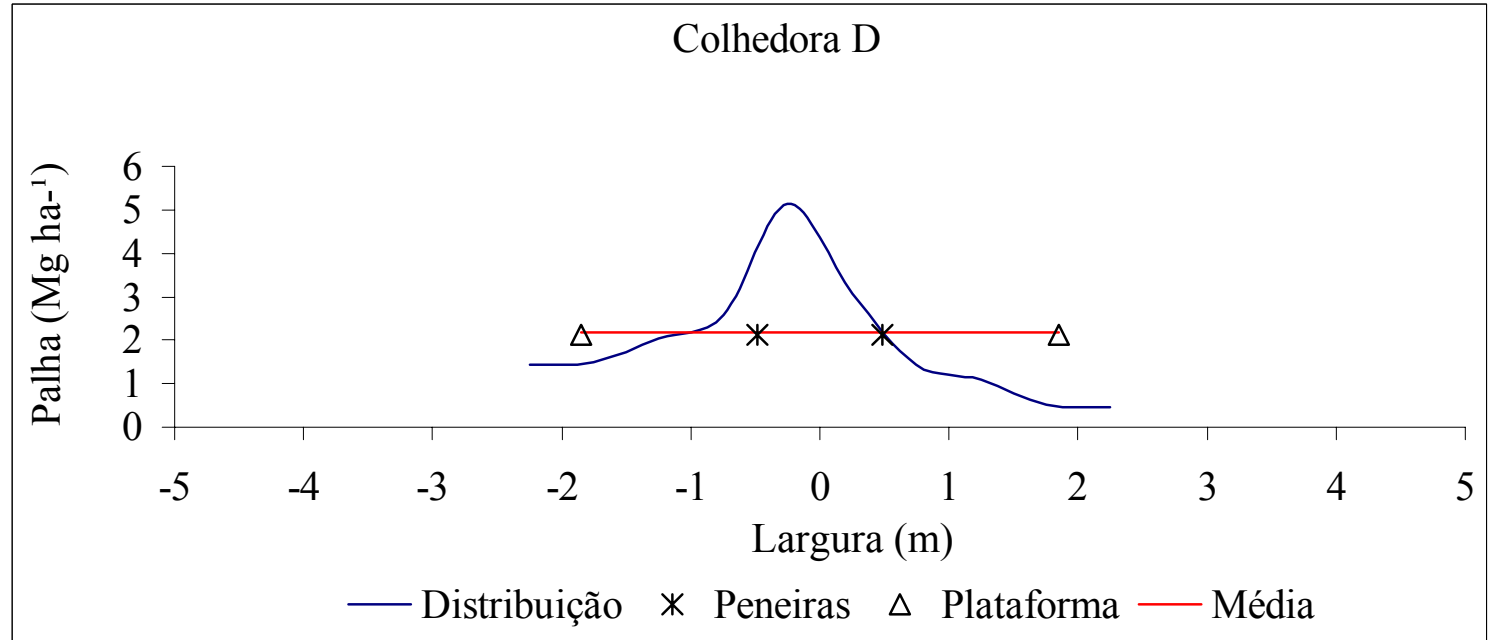

FIGURA 7. Distribuição de palha da colhedora D. Straw distribution of the combine D. 


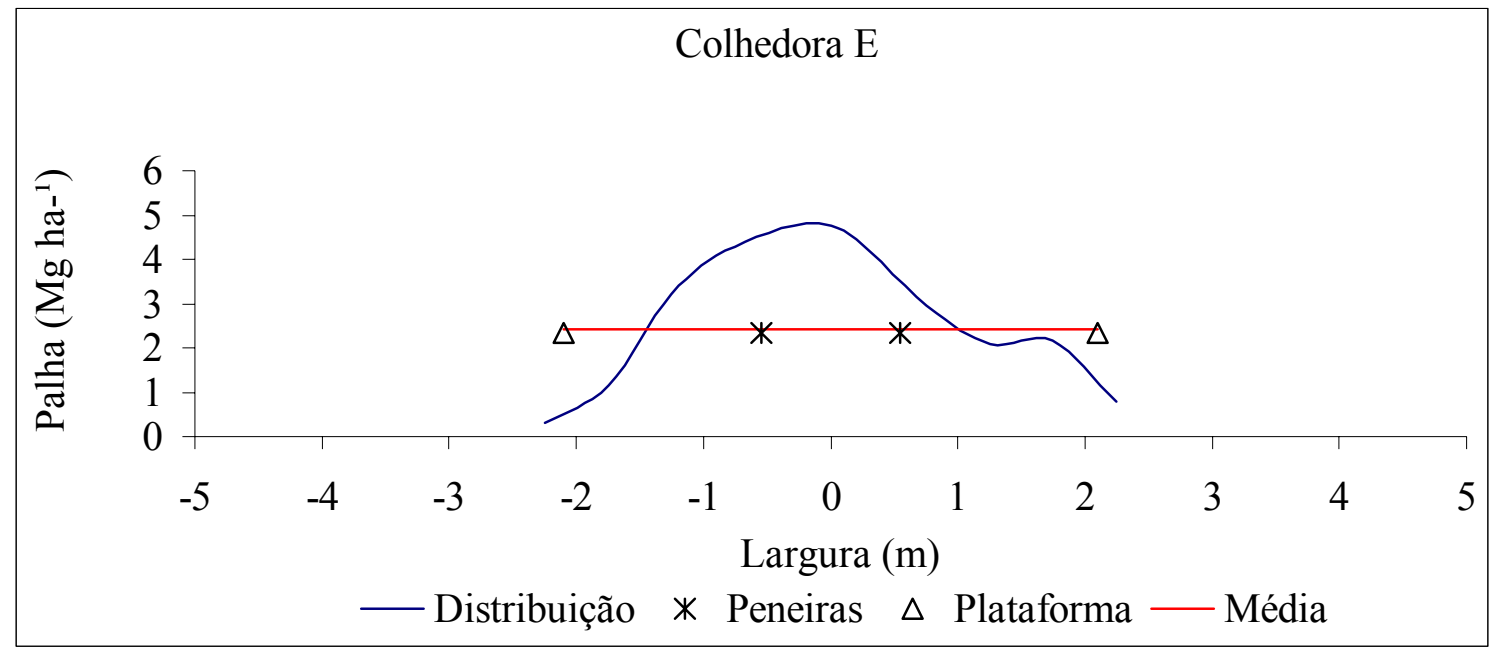

FIGURA 8. Distribuição de palha da colhedora E. Straw distribution of the combine E.

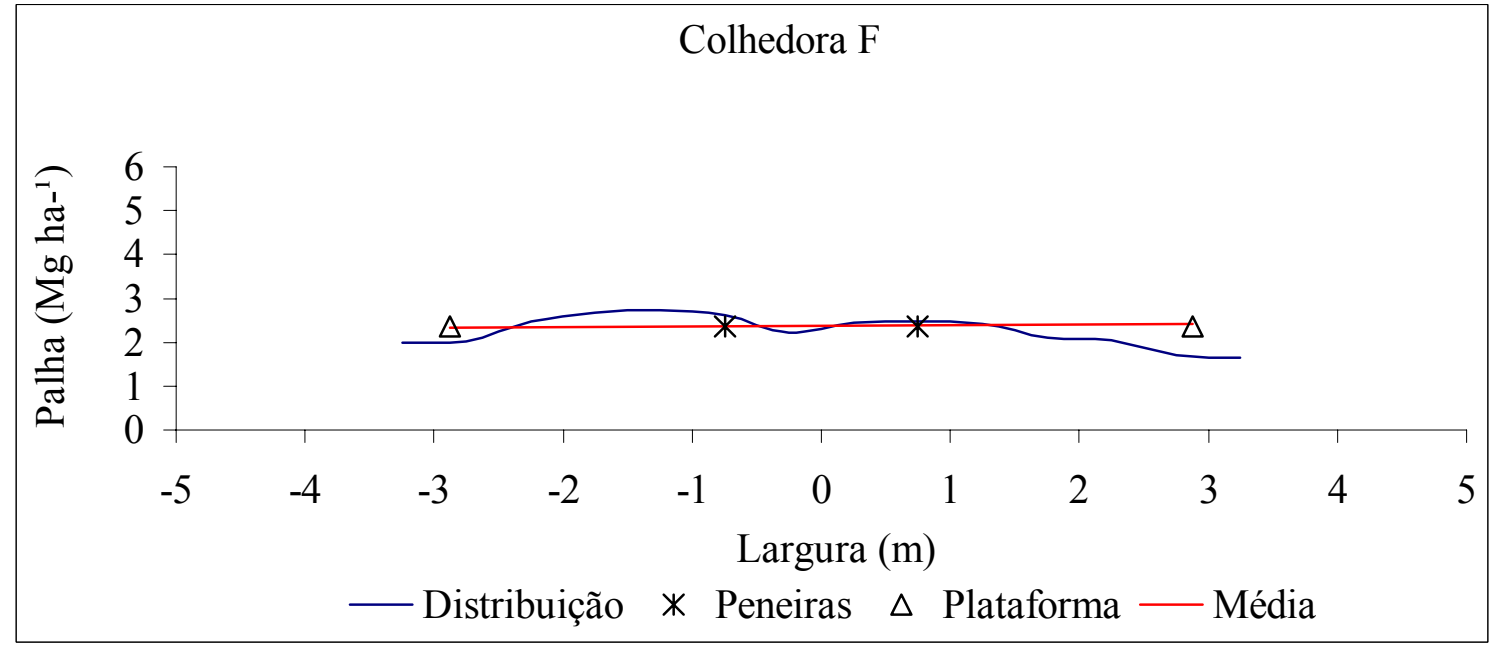

FIGURA 9. Distribuição de palha da colhedora F. Straw distribution of the combine F.

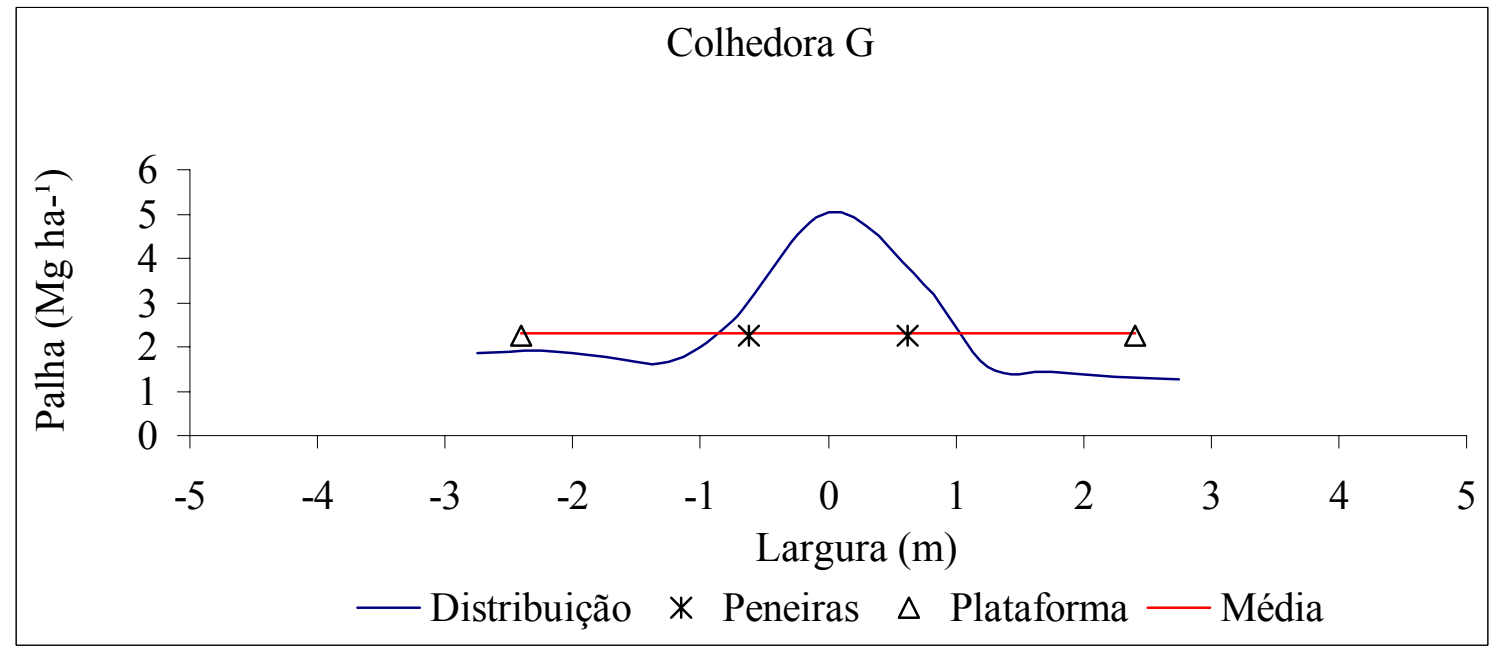

FIGURA 10. Distribuição de palha da colhedora G. Straw distribution of the combine G. 


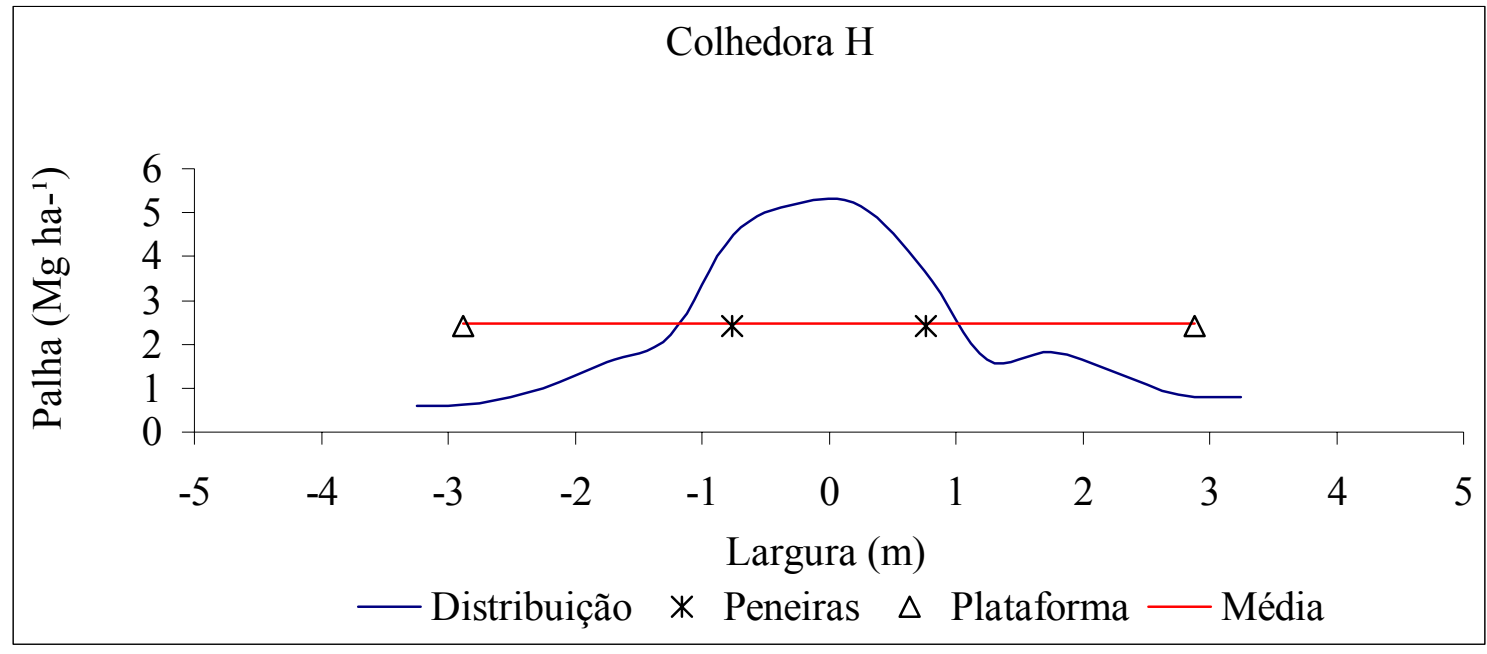

FIGURA 11. Distribuição de palha da colhedora H. Straw distribution of the combine $\mathbf{H}$.

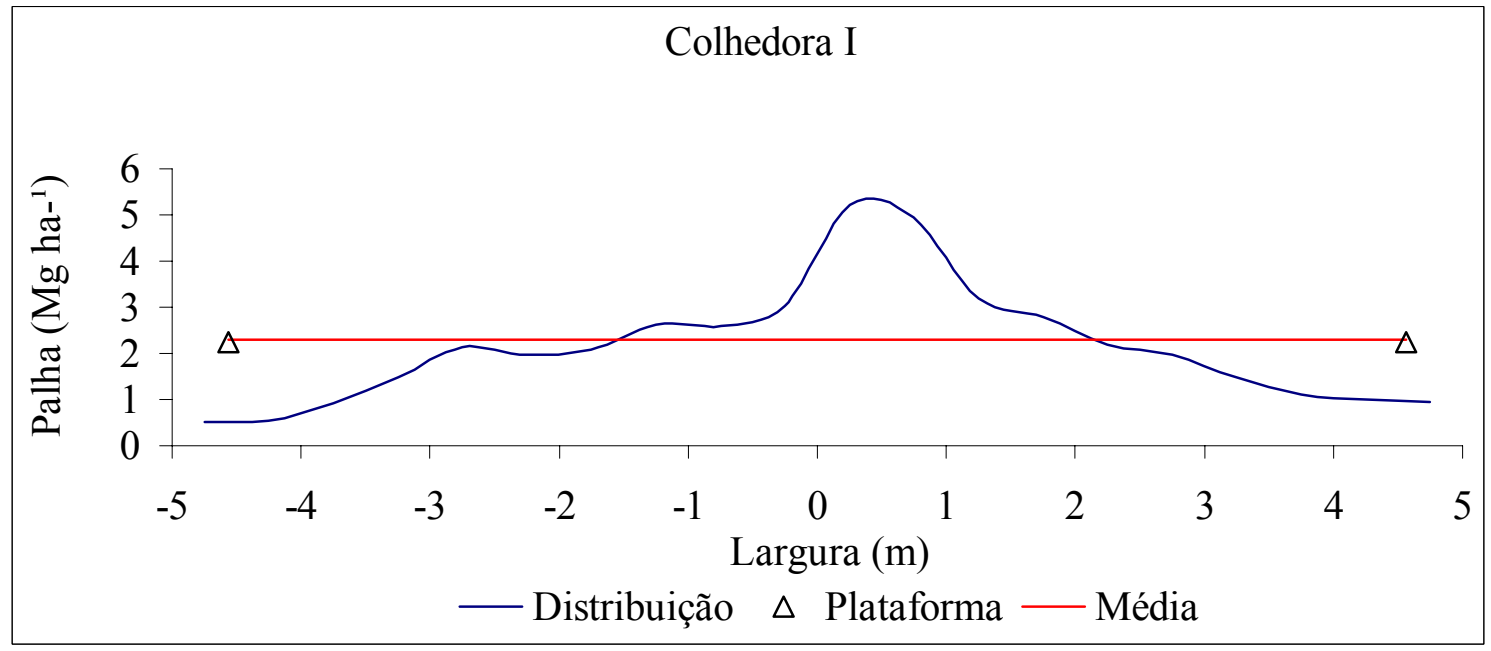

FIGURA 12. Distribuição de palha da colhedora I. Straw distribution of the combine I.

As colhedoras A, C e D, equipadas com plataforma de corte de 3,96 $\mathrm{m}$ de largura, apresentaram distribuição irregular com acentuada concentração de palha no centro da linha de deslocamento da colhedora, demonstrando que, mesmo trabalhando com plataformas de corte menores, a distribuição não é uniforme, discordando do relato de VESETH et al. (1997) e concordando com os resultados obtidos por ORLANDO et al. (2005a).

Essa dificuldade de distribuir a palha de maneira uniforme pode estar relacionada às regulagens das aletas do picador, pois a colhedora $\mathrm{B}$, também equipada com plataforma de 3,96 m de largura, distribuiu a palha com C.V. de $41 \%$, diferindo das colhedoras A, C e D. Outro fator que pode ter influenciado na distribuição, é a umidade da palha, bastante elevada no caso da colhedora $\mathrm{B}$, como pode ser visto na Tabela 2 .

Quando a palha da cultura se encontra úmida, a maior parte da massa passa pelo saca-palha e, por conseqüência, no picador da colhedora, que a fragmenta e a distribui. Quando a palha da cultura está muito seca, como aconteceu durante a avaliação das colhedoras $\mathrm{G}$ e $\mathrm{H}$, o cilindro de trilha da colhedora quebra as plantas em fragmentos menores, que não ficam retidos no saca-palha da máquina, e caem sobre as peneiras. Assim, nas colhedoras que não possuem mecanismo distribuidor para a palha proveniente das peneiras, essa é jogada diretamente sobre o solo, ficando concentrada na parte central, como pode ser observado na distribuição das colhedoras G (Figura 10) e H (Figura 11). Outro fator que pode ter influenciado na distribuição da palha é sua massa, pois quando o material é muito leve, torna-se difícil arremessá-lo a distâncias maiores. Assim, o material mais 
úmido é arremessado com maior facilidade para os lados e não fica concentrado no centro da colhedora.

A colhedora E, apesar da alta umidade da palha (35\%), não apresentou distribuição uniforme. Isso pode ter ocorrido pelo fato de essa colhedora não possuir regulagens nas aletas do picador, não proporcionando, dessa forma, opções para distribuir a palha de maneira mais adequada. Além disso, as aletas, em número de oito, são curtas e fixadas com pouca angulação, de maneira que não arremessam a palha para os lados de maneira eficiente, mas somente para trás, o que, juntamente com a palha das peneiras, resulta em faixas de distribuição com quantidades muito elevadas no centro e pouco nas extremidades.

A colhedora I possui sistema de trilha axial, diferente das demais colhedoras avaliadas e, por isso, possui sistema composto por dois discos horizontais com aletas, que distribuem toda a palha que passa no interior da colhedora. A distribuição transversal dessa colhedora, no entanto, também foi bastante irregular, com C.V. de $61 \%$, e, apesar do sistema distribuidor, apresentou elevada concentração de palha no centro, com tendência para o lado direito, devido, possivelmente, à direção de rotação do rotor (sistema de trilha) da máquina, que conduz mais palha sobre o disco do lado direito, concordando com resultados obtidos por ORLANDO et al. (2005b) e VESETH (1997). $\mathrm{Na}$ análise multivariada (Figura 3), essa colhedora aparece no mesmo grupo das colhedoras A, D e E, demonstrando que, em termos de distribuição da palha, apresentou comportamento semelhante a essas, apesar de possuir características e dimensões diferentes dessas máquinas e ser 22 e 13 anos mais nova, respectivamente.

De modo geral, nota-se que, com exceção da colhedora F, houve grande desuniformidade de distribuição dos resíduos. Esse fato também é relatado por DOUGLAS et al. (1984), citado por VESETH (1997) e ORLANDO et al. (2005a), na cultura de trigo, com colhedoras de sistema de trilha radial. Além disso, segundo o último autor, todas as colhedoras que não possuem distribuidor para o resíduo proveniente das peneiras, independentemente da largura de corte, provocam faixas com acúmulo de resíduos no centro da colhedora, nas culturas do trigo e da soja.

\title{
CONCLUSÕES
}

A distribuição transversal de palha das colhedoras avaliadas foi desuniforme, independentemente do mecanismo de trilha e da largura da plataforma de corte.

A colhedora equipada com distribuidor de palhiço proveniente das peneiras apresentou a distribuição mais próxima do limite considerado aceitável.

A umidade da palha influencia na distribuição da mesma pela colhedora.

Com exceção da colhedora equipada com distribuidor de palhiço, as colhedoras apresentaram acúmulo de palha na parte central, mais especificamente na largura compreendida pelas peneiras.

\section{REFERÊNCIAS}

AGRICULTURE, FOOD AND RURAL DEVELOPMENT. Residue management for successful direct seeding. Disponível em: http://www1.agric.gov.ab.ca/\$department/deptdocs.nsf/all/agdex1205. Acesso em: 2 out. 2007.

ALBERTA, M.E. Equipment issues in crop residue management for direct seeding. Revised November 1999. Disponível em: http://www1.agric.gov.ab.ca/\$department/deptdocs.nsf/all/agdex1352. Acesso em: 4 out. 2007.

\author{
ASAE. AMERICAN SOCIETY OF AGRICULTURAL ENGINEERING. S396.2. Combine \\ capacity and performance test procedure. St. Joseph, 1998.
}

GOMES, F.P. Curso de estatística experimental. Piracicaba: Universidade de São Paulo. Escola Superior de Agricultura "Luiz de Queiroz", 1982. 430 p. 
LEVIEN, R.; BEUTLER, J.F.; TREIN, C.R.; CONTE, O. Grau de fragmentação e forma de distribuição de resíduos pela colhedora na colheita de soja. IN: REUNIÃO BRASILEIRA DE MANEJO E CONSERVAÇÃO DO SOLO E ÁGUA, 15., 2004, Santa Maria. Anais... UFSM/SBCS, 2004. 1 CD- ROM.

ORLANDO, A.F.; FEY, E.; PEDRON, T.; LIMA, E.; PRIMO, L. Uniformidade de distribuição dos resíduos da cultura do trigo em colhedoras autopropelidas In: JORNADA CIENTÍFICA DA UNIOESTE, 3., 2005, Marechal Cândido Rondon. Anais... Cascavel: UNIOESTE, 2005a. 1 CDROM.

ORLANDO, A.F.; FEY, E.; PRIMO, L.; FURLAN, F.; DALLABRIDA, W.R. Uniformidade da distribuição de restos culturais da soja em colhedoras autopropelidas. In: CONGRESSO BRASILEIRO DE ENGENHARIA AGRÍCOLA, 34., 2005, Canoas. Anais... Jaboticabal: Associação Brasileira de Engenharia Agrícola, 2005b. 1 CD-ROM.

SMITH, J.A . Distribution of crop residue: a requirement for conservation tillage. University of Nebraska Lincoln. Cooperative Extension. Institute of Agriculture and Natural Resources, 1986. Disponível em: www.ianr.unl.edu/pubs/fieldcrops/g782.htm. Acesso em: 15 set. 2005.

VESETH. R.; ENGLE. C.; VOMOCIL. J.; McDOLE. R. Uniform combine residue distribution for successful no-till and minimum tillage systems. Crop management series no-till and minimum tillage farming. Disponível em: http://pnwsteep.wsu.edu/tillagehandbook/chapter3/030786.htm. Acesso em: 2 out. 2007. 